\title{
INDICADORES EDUCACIONAIS PARA FORMAÇÃO DE DOCENTES: USO DE DADOS LONGITUDINAIS
}

RACHEL PEREIRA RABELO SUZANA MARTA CAVENAGHI

\section{RESUMO}

Este artigo propõe uma metodologia de uso dos dados longitudinais dos censos da educação básica e da superior para o cálculo de indicadores que permitem traçar um panorama sobre a formação de docentes no ensino básico no Brasil. Para isso, realizou um estudo da trajetória escolar dos alunos dos cursos de licenciatura e da trajetória profissional dos docentes das disciplinas de Física, Química, Biologia e Matemática, utilizando análises prospectivas das bases de dados, vista a potencialidade do acompanhamento longitudinal dos alunos e docentes. Os resultados encontrados para os indicadores propostos apontam para uma dificuldade de aumento da oferta de docentes nas disciplinas estudadas, em função das baixas taxas de conclusão nos cursos de licenciatura analisados, acompanhadas ainda do aumento do tempo de conclusão nesses cursos entre os anos de 2009 e 2013 e, por outro lado, da baixa permanência de docentes na regência das disciplinas estudadas em postos da educação básica.

PALAVRAS-CHAVE INDICADORES EDUCACIONAIS • FORMAÇÃO DE PROFESSORES • EDUCAÇÃO BÁSICA • ENSINO SUPERIOR. 


\section{INDICADORES EDUCACIONALES PARA LA FORMACIÓN DE DOCENTES: USO DE DATOS LONGITUDINALES}

RESUMEN

Este artículo propone una metodología de uso de los datos longitudinales de los censos de educación básica y superior para el cálculo de indicadores que permiten trazar un panorama sobre la formación de docentes para la educación básica en Brasil. Para ello, realizó un estudio de la trayectoria escolar de los alumnos de los cursos de licenciatura y de la trayectoria profesional de los docentes de las asignaturas de Física, Química, Biología y Matemáticas, utilizando análisis prospectivos de las bases de datos, en vista de la potencialidad del seguimiento longitudinal de alumnos $y$ docentes. Los resultados encontrados para los indicadores propuestos señalan una dificultad de aumento de la oferta de docentes en las disciplinas estudiadas, en función de las bajas tasas de conclusión en los cursos de licenciatura analizados, además del aumento del tiempo de conclusión en tales cursos entre los años de 2009 y 2013 y, por otro lado, de la baja permanencia de docentes en la regencia de las asignaturas estudiadas en puestos de la educación básica.

PALABRAS CLAVE INDICADORES EDUCACIONALES - FORMACIÓN DE PROFESORES • EDUCACIÓN BÁSICA • EDUCACIÓN SUPERIOR.

\section{EDUCATIONAL INDICATORS FOR TEACHER TRAINING: THE USE OF LONGITUDINAL DATA}

ABSTRACT

This paper proposes a methodology for using longitudinal data taken from the censuses of basic and higher education to calculate indicators, that allows for design an overview of teacher training for basic education in Brazil. Therefore, we conducted a study of the paths taken by undergraduate students and teachers of physics, chemistry, biology and mathematics. The study used prospective analyses of databases, due to the potential for longitudinal follow-up of students and teachers. The results found for the proposed indicators point to a difficulty of increasing the number of teachers in the subjects studied. This results from the low completion rate of the undergraduate courses analyzed, together with the longer completion time for these courses between 2009 and 2013 as well as the low retention of teachers in the disciplines studied in basic education.

KEYWORDS EDUCATIONAL INDICATORS - TEACHER TRAINING - BASIC EDUCATION • HIGHER EDUCATION. 


\section{INTRODUÇÃO}

A discussão sobre a escassez e inadequação da formação de professores na educação básica no Brasil tem suscitado iniciativas do governo federal na criação e incentivo aos cursos de licenciatura e na oferta de cursos de complementação pedagógica para os docentes que já estão na sala de aula sem a respectiva formação para a disciplina lecionada (NASCIMENTO; SILVA; SILVA, 2014; PINTO, 2014; BRASIL, 2007).

Nos últimos dez anos, foi implementada uma série de programas do governo federal com foco na formação docente. Em 2007, a Coordenação de Aperfeiçoamento de Pessoal de Nível Superior (Capes), fundação do Ministério da Educação (MEC), foi reestruturada e criada a Diretoria de Educação Básica Presencial (DEB) pela Lei n. 11.502, de 11 de julho de 2007, que lhe conferiu atribuições de induzir e fomentar a formação inicial e continuada de profissionais da educação básica e estimular a valorização do magistério em todos os níveis e modalidades de ensino. Assim, encontram-se sob sua responsabilidade os seguintes programas: Programa de Formação Inicial e Continuada, Presencial e a Distância 
de Professores para a Educação Básica (Parfor), Programa Institucional de Bolsa de Iniciação à Docência (Pibid), Programa de Consolidação das Licenciaturas (Prodocência), Programa Novos Talentos e Universidade Aberta do Brasil (UAB).

Além dos programas voltados para formação docente, destacam-se a concessão prioritária de bolsas aos cursos de licenciaturas dos programas de financiamento da educação superior, Programa Universidade para Todos (ProUni) e Fundo de Financiamento Estudantil (Fies), e o aumento do número de vagas desses cursos na rede federal de ensino com a criação dos institutos federais, pela Lei n. 11.892, de 29 de dezembro de 2008. 1

Em junho de 2014, foi aprovado o Plano Nacional da Educação (PNE) 2014-2024 pela Lei n. 13.005, que incluiu uma meta específica para a promoção da formação adequada aos professores em sala de aula. Essa inclusão de meta específica para formação de professores no PNE 2014-2024 sinalizou o interesse do governo federal em sanar as carências do sistema de ensino brasileiro no que tange à profissionalização do quadro de docentes na educação básica, crucial para a qualidade da educação.

Porém, o foco na expansão dos cursos de licenciatura parece se revelar insuficiente para o atendimento da demanda atual do sistema de ensino, vista a dificuldade de preenchimentos dessas vagas, a baixa taxa de conclusão desses cursos e ainda o descasamento entre a formação profissional e a ocupação desses profissionais no mercado de trabalho. Schwartzman (2012), em seu estudo sobre a educação de nível superior, utilizando os dados do Censo Demográfico 2010, mostrou, a partir da análise conjunta de atividades desempenhadas no mercado de trabalho e área de formação profissional da população ocupada, que $60,8 \%$ da população com formação de professor trabalham na área de educação no Brasil. O cálculo dessa informação a partir dos dados do Censo Demográfico 2010 demonstra que apenas 42,4\% dos docentes especialistas de disciplinas atuam como professores. Já quando atuam como professores do ensino fundamental ou ensino médio, esses profissionais correspondem a $36,7 \%$ no ano 2010 e $34,9 \%$ no ano 2000.
1 A criação dos Institutos Federais teve como um dos objetivos direcioná-los para oferta de "cursos de licenciatura, bem como programas especiais de formação pedagógica, com vistas à formação de professores para a educação básica, sobretudo nas áreas de ciências e matemática, e para a educação profissional" (BRASIL, Lei 11.892 de 2008 , art. 7 VI, b). 
A dificuldade de atendimento do sistema de ensino por professores nas disciplinas específicas dos anos finais do ensino fundamental e do ensino médio foi sinalizada em estudos realizados pelo Instituto Nacional de Estudos e Pesquisas Educacionais Anísio Teixeira (Inep) em Sampaio et al. (2002) e pelo Conselho Nacional de Educação (BRASIL, 2007). Esses estudos estimaram, a partir dos dados do Censo da Educação Básica 2005, uma demanda de 246.085 postos de trabalho para o ensino médio e 479.906 para os anos finais do ensino fundamental (BRASIL, 2007 apud RUIZ, 2008).

Uma nova análise realizada pelo Instituto Nacional de Estudos e Pesquisas Educacionais Anísio Teixeira (BRASIL, 2015) atualizou as estimativas da demanda por docentes das disciplinas do ensino médio regular. Segundo estimativas encontradas, a demanda para o ano 2013 por professores no ensino médio seria de 256.734 , somadas todas as disciplinas de uma grade curricular hipotética (BRASIL, 2015). No que se refere às disciplinas de Biologia, Física e Química, essa demanda seria de 26.848 docentes e, na disciplina de Matemática, de 33.560 docentes. A análise aponta ainda que apenas 26,8\% do total de professores de Física possuem formação adequada para ministrar a disciplina e que, nas disciplinas de Química, Matemática e Biologia, esses percentuais são $43,2 \%, 66,5 \%$ e $66,9 \%$, respectivamente.

Nesse contexto, este artigo tem como objetivo apresentar uma metodologia de cálculo de indicadores sobre formação de docentes para monitoramento do atendimento do sistema de ensino brasileiro por esses profissionais, nas disciplinas específicas da educação básica, com base em dados longitudinais. Para isso, realizou uma análise sobre a trajetória escolar e profissional dos alunos dos cursos de Licenciatura em Física, Química, Biologia e Matemática e docentes dessas disciplinas a partir do uso dos dados longitudinais dos censos da educação básica e superior, respectivamente.

\section{TRAJETÓRIA DISCENTE E DOCENTE}

Estudos sobre a trajetória escolar têm contribuído para o diagnóstico do sistema educacional e para a avaliação das 
políticas públicas. Essa análise tem sido feita a partir do uso de métodos estatísticos indiretos que permitem a identificação das séries/anos/etapas de ensino nas quais ocorre maior estancamento do fluxo escolar (situações de reprovação, defasagem e evasão). No Brasil, destacam-se o Modelo Profluxo (FLETCHER; RIBEIRO, 1996; FLETCHER, 1997) - também aplicado por outros autores (GOLGHER, 2004) -, a Probabilidade de Progressão por Série (PPS), desenvolvida por Rios-Neto (2004), e as Tábuas de Aprovação, elaboradas por Rigotti e Hadad (2001).

O Modelo Profluxo permitiu identificar a repetência como principal problema do sistema de ensino brasileiro, em substituição ao diagnóstico, predominante até a década de 1980, da evasão escolar (GOLGHER, 2004). A partir desse novo diagnóstico, foram realizadas algumas adaptações no cálculo dos indicadores de aprovação, reprovação e abandono, elaborados por Rubem Klein em 1995 (apud GOLGHER, 2004), os quais inseriram especificidades do sistema de ensino brasileiro no Modelo de Fluxo Escolar da Organização das Nações Unidas para a Educação, a Ciência e a Cultura (Unesco). Esses indicadores são calculados por método direto, utilizando as informações coletadas pelo Censo Escolar realizado anualmente pelo Inep. No entanto, o cálculo desses indicadores restringe-se ao ensino fundamental e médio, visto que a metodologia de cálculo dos indicadores é baseada na análise do fluxo escolar sob uma visão seriada do sistema, mais apropriada à educação básica.

Os requisitos para progressão e conclusão de curso no ensino superior possuem características diversas, que não correspondem necessariamente à progressão por séries, vistas as especificidades da organização dos cursos nesse nível de ensino. No entanto, segundo Klein (2009, p. 15),

Seria importante saber em que áreas, cursos, instituições há mais repetência, evasão, suas taxas de conclusão, tempos médios de conclusão, em suma, a eficiência de cada curso e área, inclusive por instituição.

Assim, este trabalho propõe uma metodologia de cálculo para indicadores de conclusão na educação superior, a partir de suposições que permitem a definição de trajetórias escolares para esse nível de ensino. 
2 BLAUG, M. Approaches to educational planning. Economic Journal, n. 77 p. 262-287, June 1967 .

3 CÖRVERS, F.; HEIJKE, H. Forecasting the labour market by occupation and education: some key issues. Atenas: Employment Observatory Research Informatics, 2004
Com relação à trajetória dos docentes, destaca-se que "não existe uma correspondência exata entre a área de formação acadêmica de uma pessoa e o tipo de ocupação que ela irá exercer no mercado de trabalho" (BLAUG, 1967² apud CÖRVERS; HEIJKE, $2004^{3}$ apud PEREIRA; NASCIMENTO; ARAÚJO, 2013, p. 524). Assim, tendo em vista o potencial da base de dados longitudinal dos profissionais estudados (docentes) no Censo da Educação Básica, este artigo ainda propõe um indicador de permanência de docentes na sala de aula.

\section{METODOLOGIA}

\section{FONTES DE DADOS}

Este artigo conta com duas importantes e detalhadas bases de dados sobre o universo estudado de alunos e docentes: Censo da Educação Básica e Censo da Educação Superior. Os dados individualizados de alunos e docentes permitem um acompanhamento longitudinal dos dados anuais dessas unidades de informação no sistema de ensino, o que potencializa os estudos sobre trajetória escolar de alunos e trajetória profissional de docentes de forma prospectiva. Esse potencial permitiu a elaboração de indicadores sobre a formação de professores no Brasil.

\section{CENSO DA EDUCAÇÃO BÁSICA}

O Censo da Educação Básica é um levantamento de dados anual de caráter censitário realizado via internet pelo Sistema Educacenso, a partir da parceria do Inep com as secretarias de educação dos estados, Distrito Federal e municípios. Abrange toda a rede de ensino (público e privado) e todas as modalidades e etapas de ensino da educação básica, sendo estas: ensino regular, ensino especial, educação profissional e educação de jovens e adultos, educação infantil, ensino fundamental e médio. A coleta de dados é dividida em duas etapas, sendo a primeira o preenchimento dos questionários da escola, da turma, do aluno e do docente, e a segunda, as informações de movimento escolar do aluno (BRASIL, 2015).

Até o ano de 2006, a unidade de informação do Censo da Educação Básica era a escola. Alunos e docentes eram contabilizados 
por agregados (matrículas e funções docentes) por estabelecimento de ensino, sexo, idade, etapa e modalidade de ensino. Em 2007, o antigo sistema de coleta, Sistema Integrado de Informações Educacionais (Sied), foi substituído pelo sistema eletrônico Educacenso (ESCOLA NACIONAL DE ADMINISTRAÇÃO PÚBLICA - ENAP, 2010), no qual foi implementada a nova metodologia de coleta de informações individualizadas de alunos, docentes e turmas (BRASIL, 2007). Essa inovação na coleta de dados de alunos e docentes e a identificação única desses nas bases de dados possibilitou, por exemplo, acompanhar um mesmo aluno e um mesmo professor em turmas diferentes, o que permite qualificar a relação destes com o sistema de ensino como um todo.

Com relação ao Censo da Educação Básica, utilizou-se a série histórica de 2009 a 2013 para a construção de um indicador de permanência de docentes na sala de aula. O Quadro 1 relaciona as variáveis empregadas dessa base de dados relativas às informações dos docentes e turmas para esse Censo.

QUADRO 1 - Relação de variáveis utilizadas no estudo longitudinal de docentes

\begin{tabular}{|l|l|}
\hline \multicolumn{1}{|c|}{ VARIÁVEIS } & \multicolumn{1}{c|}{ DESCRIÇÃO } \\
\hline FK_COD_DOCENTE & CÓDIGO DE IDENTIFICAÇÃO ÚNICA DO DOCENTE \\
\hline IN_DISC_QUÍMICA & VÍNCULO DO DOCENTE NA DISCIPLINA DE QUÍMICA \\
\hline IN_DISC_FÍSICA & VÍNCULO DO DOCENTE NA DISCIPLINA DE FÍSICA \\
\hline IN_DISC_MATEMÁTICA & VÍNCULO DO DOCENTE NA DISCIPLINA DE MATEMÁTICA \\
\hline IN_DISC_BIOLOGIA & VÍNCULO DO DOCENTE NA DISCIPLINA DE BIOLOGIA \\
\hline
\end{tabular}

Fonte: Censo da Educação Básica/Inep/MEC.

\section{CENSO DA EDUCAÇÃO SUPERIOR}

O Censo da Educação Superior teve origem nos levantamentos estatísticos sistemáticos e anuais do Serviço de Estatística da Educação e Cultura (Seec) do Ministério da Educação, em trabalho conjunto com o Instituto Brasileiro de Geografia e Estatística (IBGE). É uma pesquisa anual censitária realizada via internet, a partir da parceria do Inep com as instituições de ensino superior (IES). Abrange os níveis acadêmicos de graduação e dos cursos sequenciais de formação específica. Atualmente a coleta de dados é realizada pelo sistema web Censup. 
4 Em termos legais, o Cadastro e-MEC tornou-se o cadastro único de IES e de cursos por meio da Portaria Normativa n. 40, de 12 de dezembro de 2007 (BRASIL, 2007). Sua finalidade é permitir a interoperabilidade dos programas da educação superior, como: Programa Universidade para Todos (ProUni), Fundo de Financiamento ao Estudante do Ensino Superior Exame Nacional de Desempenho de Estudantes (Enade), Sistema Nacional de Avaliação da Educação Superior (Sinaes), Sistema de Seleção Unificada (Sisu), Universidade Aberta do Brasil (UAB), etc.
O Censup, assim como o Educacenso, implementou a coleta individualizada de informações de alunos e docentes, ampliando a unidade de investigação para alunos e docentes. Até o ano de 2008, a unidade de investigação da pesquisa correspondia ao curso da IES. Em 2010, o Censup foi integrado ao Cadastro e-MEC, ${ }^{4}$ que passou a ser o cadastro único de cursos e IES da educação superior, aos quais todos os programas e políticas da educação superior ficaram vinculados. Essa integração correspondeu a novas mudanças metodológicas de coleta do Censo da Educação Superior, no que se refere às informações de categoria administrativa das IES, local de oferta, grau acadêmico do curso e informações de instalações (BRASIL, 2010).

Para a construção dos indicadores de conclusão de alunos, utilizou-se a série histórica de 2009 a 2013. O Quadro 2 relaciona as variáveis utilizadas dessa base de dados relativas às informações dos alunos e cursos.

QUADRO 2 - Relação de variáveis utilizadas no estudo longitudinal de alunos

\begin{tabular}{|c|c|}
\hline VARIÁVEIS & DESCRIÇÃO \\
\hline CO_ALUNO & Código do aluno \\
\hline CO_CURSO & Código do curso \\
\hline NO_CURSO & Nome do curso \\
\hline ANO_INGRESSO & Ano de ingresso do aluno no curso \\
\hline IN_SEXO_ALUNO & Sexo \\
\hline CO_SITUAÇÃO_ALUNO & Situação de vínculo no curso em 31/12 do ano de referência do Censo \\
\hline CO_GRAU_ACADÊMICO & Grau acadêmico do curso \\
\hline CO_OCDE & 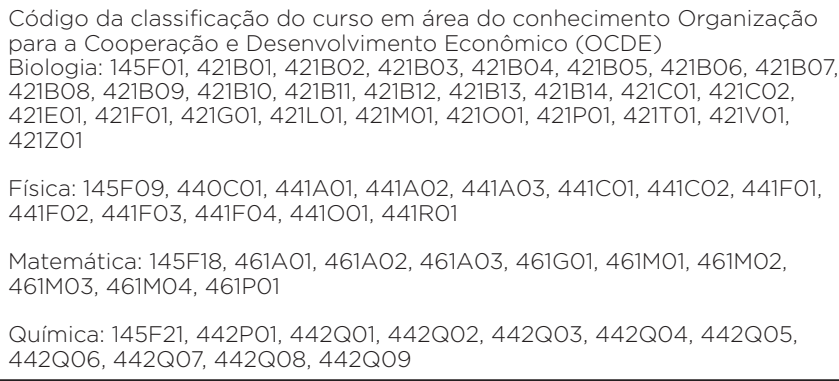 \\
\hline NO_OCDE & Nome da classificação do curso em área do conhecimento OCDE \\
\hline CO_MODALIDADE_ENSINO & Modalidade de ensino do curso \\
\hline CO_CATEGORIA_ADMINISTRATIVA & Categoria administrativa da IES \\
\hline
\end{tabular}

Fonte: Censo da Educação Superior/Inep/MEC. 


\section{DEFININDO TRAJETÓRIAS DISCENTES E DOCENTES}

A coleta individualizada de dados de alunos e docentes, implementada em 2007 no Censo da Educação Básica (Educacenso) e em 2009 no Censo da Educação Superior (Censup), ampliou a unidade básica da informação educacional utilizada até então nos levantamentos censitários e deu início ao cadastro de docentes e alunos. Ao ser incluído no cadastro, cada aluno ou docente recebe um código de identificação pessoal gerado pelo próprio sistema (ID), que permite identificá-lo como indivíduo, independentemente da instituição de ensino ou turma/curso a que está vinculado. Após o primeiro cadastro do ID do aluno e do professor nos sistemas de coleta - Educacenso e Censup -, o mesmo é mantido na base de dados cadastrais ao longo dos anos, sendo que as instituições de ensino apenas atualizam os dados variáveis, ou seja, aqueles relativos à trajetória escolar do aluno e à trajetória ocupacional dos docentes. Como o ID é o mesmo a cada edição (ano) dos censos educacionais, é possível o acompanhamento longitudinal dessas duas unidades de pesquisa, o que permite estudos mais detalhados da trajetória escolar dos alunos e da carreira docente (BRASIL, 2009), não apenas de maneira retrospectiva, mas principalmente prospectiva.

\section{TRAJETÓRIAS DISCENTES NO ENSINO SUPERIOR}

A proposta inicial do indicador de conclusão dos alunos foi construída a partir de uma análise longitudinal prospectiva, com objetivo de aferir a taxa de conclusão de uma coorte real, desde $o$ ano de ingresso $t$ até $t+7$. Nesse caso, foi considerado que o prazo máximo de integralização do curso seria oito anos, visto que se espera que a trajetória escolar de toda a coorte estudada se encerre em até sete ou oito anos, prazo em que normalmente o aluno é jubilado em cursos de duração de quatro anos. Importante destacar que essa metodologia para cálculo de indicadores de conclusão pode ser aplicada para coortes de alunos que já completaram o curso, e ainda para coortes mais recentes, a partir da estimação dos últimos anos da trajetória ainda não percorrida, como será detalhado mais adiante. 
O acompanhamento longitudinal dos alunos foi realizado a partir do pareamento das variáveis identificadoras do aluno e do curso ao qual estava vinculado ao longo do período estudado. Devido à pluralidade de denominações dos cursos (NO_CURSO), presente nos microdados para as categorias de cursos estudadas, optou-se, para definição de curso, considerar o grau acadêmico de licenciatura e, em 2009, também bacharelado e licenciatura e selecionar as categorias da Classificação OCDE (Organização para a Cooperação e Desenvolvimento Econômico) (BRASIL, 2001) relacionadas no Quadro 1 para cada um dos cursos.

As estimativas de egressos nos cursos de licenciatura em Física, Química, Biologia e Matemática foram realizadas com base no acompanhamento longitudinal dos alunos que ingressaram em 2009 nos cursos estudados a partir do pareamento das variáveis identificadoras do aluno (CO_ALUNO) e do curso de licenciatura ao qual estava vinculado ao longo do período estudado (2009 a 2013).

As definições da situação de vínculo do aluno ao curso permitiram estabelecer uma tipificação de vinculação do aluno ao curso e realizar um mapeamento das combinações de trajetórias escolares encontradas a partir do pareamento das bases de dados ano a ano. Para caracterização dessa trajetória discente, utilizou-se a variável situação de vínculo do aluno ao curso, a qual possui como data de referência o dia 31 de dezembro do respectivo ano de referência do Censo. $\mathrm{O}$ aluno que ingressou em algum tempo (t) do ano de 2009 possuirá, em 31 de dezembro de 2009, alguma das seguintes situações de vínculo ao curso: "provável formando", "cursando", "matrícula trancada", "desvinculado do curso", "transferido para outro curso na mesma IES", "formado" ou "falecido". Segundo o resumo técnico do Censo da Educação Superior de 2010 (BRASIL, 2012), a categoria "provável formando" foi coletada apenas no ano de 2009 e retirada no ano seguinte, quando foi inserida a categoria "transferido para outro curso na mesma IES".

A partir das definições da situação de vínculo do aluno ao curso, foram estabelecidos dois tipos de vinculação do aluno ao curso em cada ano: 1) vínculo ao curso ativo: "provável formando", "cursando" ou "matrícula trancada"; e 2) vínculo 
ao curso encerrado: "desvinculado do curso", "formado", "falecido" ou "transferido para outro curso na mesma IES".

Com base nessa tipificação e no mapeamento das categorias de trajetória escolar dos alunos (Apêndice 1), foram determinadas seis categorias de trajetória escolar dos alunos estudados, as quais buscam definir os casos de conclusão a partir da categorização da combinação dos tipos de vínculos dos alunos ano a ano, incluindo o tratamento dos casos de inconsistência da base de dados, ${ }^{5}$ sendo:

1. vínculo final indeterminado: alunos encontrados no mesmo curso em todos os anos estudados, mas que apresentavam vínculo ativo em 2013 (sem conclusão anterior);

2. conclusão: alunos que concluíram o curso em algum momento do período analisado, ou seja, foram informados como "formados" em algum momento do tempo. Devido à identificação de algumas inconsistências de trajetória, criaram-se três subcategorias para esse grupo: 2.1) conclusão ideal - conclusão no último ano da trajetória, com vínculo anterior ativo; 2.2) conclusão com trajetória inconsistente - conclusão no último ano da trajetória, mas com vínculo anterior inativo; e 2.3) conclusão imprecisa - conclusão em ano anterior ao último da trajetória, com retorno após conclusão;

3. perda: alunos que apresentam vínculos ativos até um ano $t$ não encontrados no(s) ano(s) subsequente(s);

4. não concluíram: alunos que finalizaram seu vínculo ao curso, na condição de "desvinculado" ou "falecido", em algum ano do período analisado e não retornaram no(s) ano(s) seguinte(s);

5. transferência de curso: alunos que se transferiram de curso dentro de uma mesma IES, em algum ano do período analisado, sem retorno a esse curso em ano(s) posterior(es);

6. perdidos com retorno: alunos que apresentam vínculo até um ano $t$, não encontrados em $t+1$, mas que retornaram em ano ou período subsequente a $t+1$ no mesmo curso.
5 Conforme definido pela tipificação dos vínculos de alunos aos cursos, os vínculos encerrados não deveriam retornar no ano seguinte de edição do Censo. Sendo assim, quando encontradas tais situações nas bases de dados, foi necessário atribuir uma categorização de trajetória escolar a cada combinação. 
O acompanhamento longitudinal dos alunos dos cursos estudados permitiu identificar o comportamento de conclusão até o último ano da análise: 2013. Porém, para aferir uma taxa de conclusão, foi necessário projetar as trajetórias dos três últimos anos. Uma das dificuldades comuns às análises longitudinais de coortes reais (CR) é que normalmente estas requerem uma longa série histórica dos dados. Apesar da disponibilidade de uma série histórica de cinco anos e de a maior parte dos cursos possuírem quatro anos de duração (tempo mínimo de integralização), um percentual considerável de alunos ainda apresentaram vínculos ativos no quinto ano de curso. Assim, recorreu-se a uma segunda possibilidade de uso dos dados disponíveis para estimar a taxa de conclusão nos três anos censurados da trajetória escolar da coorte estudada.

A partir da combinação das informações de conclusão e data de ingresso numa única base de dados (anual), construiu-se uma análise transversal retrospectiva do fenômeno de conclusão, vista a possibilidade de verificação do tempo de curso de cada aluno. As medidas de período representam a ótica transversal de um fenômeno, com a vantagem de serem medidas em apenas um ano, o que permite superar as dificuldades das CR (longo tempo de observação); no entanto, a maior restrição destas é que somente se observam retrospectivamente aqueles que estavam presentes no período observado (os sobreviventes).

A comparação da distribuição do número de concluintes sob as óticas transversal e geracional em cada disciplina permitiu constatar um comportamento-padrão para todas elas. Esse comportamento caracterizou-se pelo crescimento do número de concluintes até um tempo $t$, quando se atinge um ponto de saturação (crescimento máximo), seguido de uma redução na velocidade de crescimento em direção a zero, próprio de uma curva de crescimento logístico. A partir da observação da similaridade do comportamento da distribuição do número de concluintes, ajustaram-se as curvas de crescimento logístico para cada disciplina, sendo que o percentual acumulado de concluintes em relação ao número de ingressos corresponde à variável dependente, e o tempo de 
curso (em anos) corresponde à variável explicativa, conforme equação:

$$
P i, t=\frac{\alpha}{1+\beta e^{-k t}}
$$

Sendo que

$\boldsymbol{P i}, \boldsymbol{t}$ é o percentual acumulado de concluintes em relação ao número de ingressos para o curso $i$ no tempo de duração de curso $t$ dado em anos;

$\alpha$ é o valor assintótico que circunda a função e especifica o nível de saturação do processo de crescimento;

$\boldsymbol{k}$ é taxa relativa de crescimento máxima;

$t$ corresponde ao tempo de curso em anos;

$\boldsymbol{\beta}$ é a abcissa do ponto de inflexão.

Os parâmetros das curvas de crescimento logístico foram estimados para cada disciplina e as assíntotas de cada curva foram definidas a partir dos dados observados. Deve-se ressaltar que essa projeção sempre será necessária quando o período de tempo analisado não permitir observar a situação final de todos os alunos. Além disso, a distribuição a ser utilizada nessa extrapolação precisa ser analisada para os diferentes cursos e contextos estudados.

\section{TRAJETÓRIAS DOCENTES DA EDUCAÇÃO BÁSICA}

Para a construção de um indicador sobre a permanência de docentes na sala de aula, na educação básica, realizou-se um acompanhamento longitudinal dos docentes a partir do pareamento da variável ID_DOCENTE, ano a ano, no período de 2009 a 2013. Com base no registro do docente na disciplina específica a partir de 2009, este foi acompanhado nos anos seguintes, determinando se estava lecionando a mesma disciplina em cada ano de referência. Dessa forma, foi possível identificar inúmeras trajetórias para os docentes, como esquematizado no Quadro 3. Algumas trajetórias possíveis são: aqueles que estavam lecionando um curso em 2009 e, sem interrupção, continuaram até 2013; aqueles que estavam lecionando em 2009, interromperam em um 
ou mais períodos, mas estavam novamente em 2013; aqueles que estavam em 2009 e em algum dos anos seguintes, interromperam e não voltaram mais a lecionar a referida disciplina.

QUADRO 3 - Esquema para mapeamento da trajetória do docente em disciplina específica - Brasil 2009 a 2013

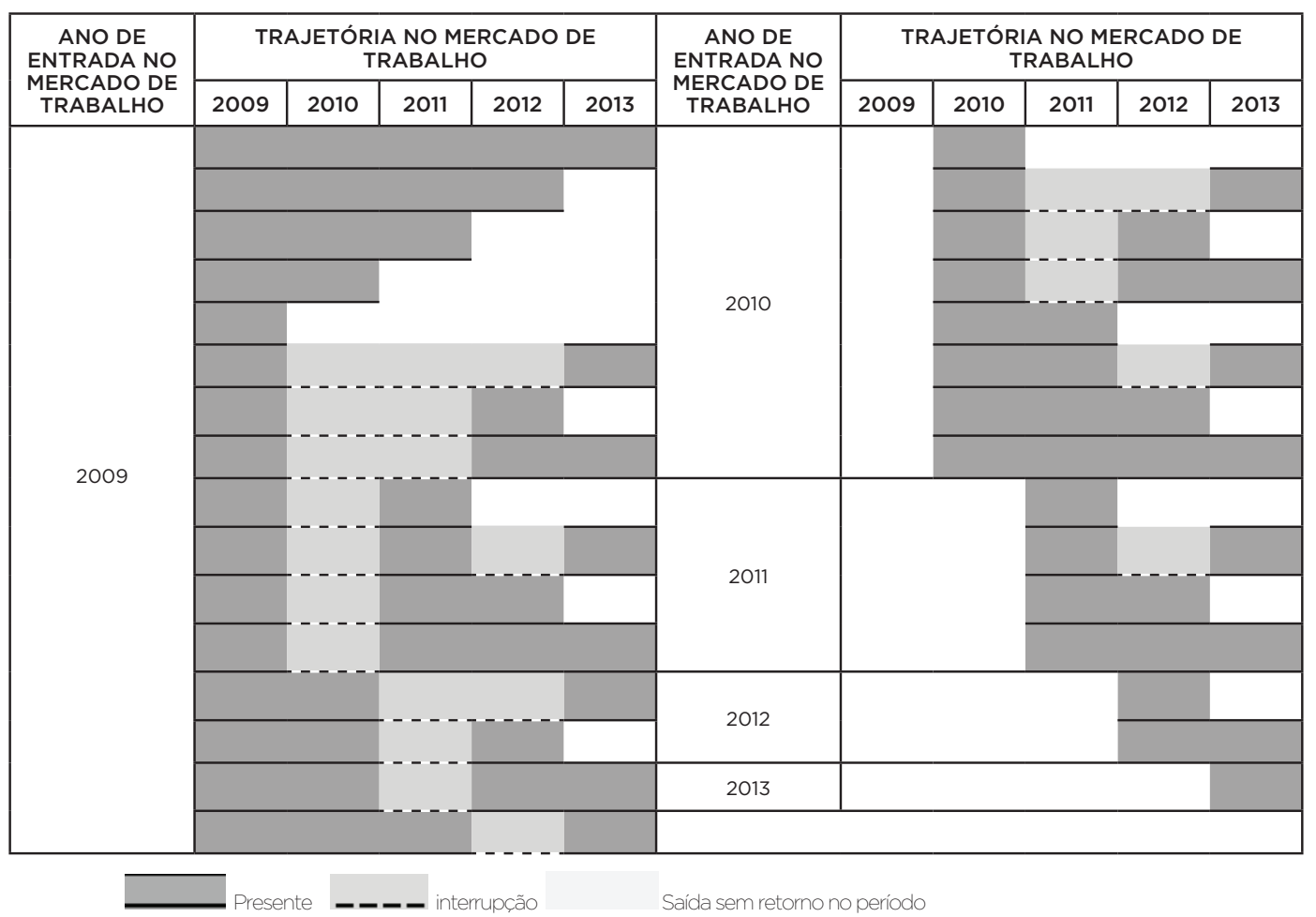

Fonte: Inep, Microdados do Censo da Educação Superior 2009 a 2013.

É importante observar que as trajetórias interrompidas antes de 2013 e sem retorno estão censuradas à direita. Dessa forma, alguns docentes podem ter voltado a lecionar o curso após 2013, e isso não está na janela de observação. Diante dessa limitação, para calcular indicadores de permanência de professores na sala de aula, recorreu-se a uma segunda ótica complementar do estudo longitudinal da trajetória docente. Na primeira ótica, estimou-se o percentual de "saídas definitivas" do sistema de ensino, a partir dos casos de 
docentes registrados no ano 2009 que não foram encontrados nas bases de dados dos anos subsequentes até 2013 . A segunda ótica estimou o percentual de permanência no sistema de ensino, a partir da comparação entre o estoque anual de docentes por disciplina em relação ao estoque de docentes no quinquênio 2009 a 2013 (sendo que o total de docentes do quinquênio foi calculado pelo acompanhamento longitudinal da variável ID_DOCENTE).

O método de acompanhamento longitudinal prospectivo das unidades de análise, alunos e docentes permitiu aferir indicadores de conclusão e retenção de docentes na sala de aula no nível de disciplinas específicas, informações importantes para a discussão sobre a oferta de docentes para a educação básica no Brasil. Os resultados apresentados para as disciplinas de Física, Química, Biologia e Matemática ilustram o alcance dos indicadores.

\section{RESULTADOS}

INDICADORES DE CONCLUSÃO NA EDUCAÇÃO SUPERIOR

O número de ingressos que constituem o universo da coorte estudada para o Brasil é de 83.427 vínculos de aluno, que correspondem a 82.294 alunos, sendo que, destes, 34.329 estavam cursando Biologia, 8.917 Física, 27.946 Matemática e 12.235 Química. Esse universo corresponde a 82.294 alunos, visto que 1.119 alunos ingressaram em mais de um curso no ano de 2009, 1.105 ingressaram em dois cursos e 14 , em três cursos.

A Tabela 1 apresenta a distribuição dos ingressos nos cursos analisados no ano de 2009, segundo sua situação de vínculo ao curso e o tipo de vínculo ao curso. De acordo com essa tipificação, verifica-se que 90,3\% desses ingressos mantiveram-se com vínculos ativos no final de 2009 e 9,7\% encerraram seu vínculo no curso no qual ingressaram já no primeiro ano. 
TABELA 1 - Distribuição dos ingressos nos cursos de Licenciatura em Biologia, Matemática, Física e Química por situação e tipo de vínculo ao curso - Brasil - 2009

\begin{tabular}{|c|c|c|c|}
\hline \multirow{2}{*}{$\begin{array}{l}\text { SITUAÇÃO } \\
\text { DE VÍNCULO } \\
\text { AO CURSO }\end{array}$} & \multirow{2}{*}{ CATEGORIAS DE VÍNCULO } & \multicolumn{2}{|c|}{ VÍNCULOS DE ALUNOS } \\
\hline & & $\mathrm{N}$ & $\%$ \\
\hline \multirow{4}{*}{ ATIVOS } & SUBTOTAL & 75.383 & 90,3 \\
\hline & 1. PROVÁVEL FORMANDO/A & 606 & 0,7 \\
\hline & 2. CURSANDO/A & 70.449 & 84,4 \\
\hline & 3. MATRÍCULA TRANCADA & 4.328 & 5,2 \\
\hline \multirow{5}{*}{ ENCERRADOS } & SUBTOTAL & 8.044 & 9,7 \\
\hline & 4. DESVINCULADO DO CURSO & 6.924 & 8,3 \\
\hline & 5. TRANSFERIDO P/ OUTRO CURSO DA MESMA IES & - & - \\
\hline & 6. FORMADO/A & 1.112 & 1,4 \\
\hline & 7. FALECIDO/A & 8 & 0,0 \\
\hline TOTAL & & 83.427 & 100,0 \\
\hline
\end{tabular}

Fonte: Inep, Microdados do Censo da Educação Superior de 2009.

Considerando a situação de vínculo do aluno ao curso, apresentada na Tabela 1, verifica-se que 1,4\% dos ingressos de 2009 se formaram já no primeiro ano, o que pode ocorrer devido ao aproveitamento de créditos de disciplinas realizadas em outro curso ou em situações de reingresso.

$\mathrm{O}$ acompanhamento longitudinal desses alunos que ingressaram em 2009 até o ano de 2013 permitiu determinar a trajetória de $67,1 \%$ dos alunos estudados, além de identificar as perdas de 8,6\% (Tabela 2). É possível aferir que, até o quinto ano de curso, 25,1\% dos ingressos de 2009 concluíram os cursos; no entanto, $24,3 \%$ dos alunos ainda continuavam com vínculo ativo.

TABELA 2 - Distribuição do número de ingressos em 2009 nos cursos de Licenciatura em Biologia, Matemática, Física e Química segundo a trajetória escolar observada até 2013 - Brasil

\begin{tabular}{l|c|c}
\hline \multirow{2}{*}{$\begin{array}{l}\text { TIPIFICAÇÃO DE TRAJETÓRIA } \\
\text { ESCOLAR ATÉ 2013 }\end{array}$} & $\mathbf{N}$ & $\%$ \\
\cline { 2 - 3 } CONCLUSÃO & 20.940 & 25,1 \\
\hline VÍNCULO FINAL INDETERMINADO & 20.279 & 24,3 \\
\hline PERDAS & 7.182 & 8,6 \\
\hline NÃO CONCLUÍRAM & 32.554 & 39,0 \\
\hline TRANSFERÊNCIA & 1.632 & 2,0 \\
\hline PERDIDOS COM RETORNO & 840 & 1,0 \\
\hline TOTAL & 83.427 & $100,0 \%$ \\
\hline
\end{tabular}

Fonte: Inep, Microdados do Censo da Educação Superior 2009 a 2013 
Para esses alunos ainda com vínculo no final de 2013, foi necessário inferir/projetar o status final, conforme descrito anteriormente. Para tal, realizou-se primeiramente uma análise do comportamento dos alunos observados de forma retrospectiva, o que também permite calcular o tempo médio de conclusão a partir dos dados transversais. ${ }^{6}$ A Tabela 3 apresenta a distribuição dos alunos que concluíram o curso em um determinado ano segundo o tempo que levaram para concluí-lo; assim, do total de concluintes de 2009, 65,1\% o fizeram com até quatro anos de curso, outros $20,2 \%$ o fizeram em cinco anos, e outros 14,7\% levaram até oito anos ou mais. Essa distribuição muda consideravelmente ao longo do tempo, indicando aumento do tempo até a conclusão do curso, fato que é confirmado pelo tempo médio de conclusão dos cursos, que varia de 4,61 anos em 2009 para 5,04 em 2013.

TABELA 3 - Distribuição relativa do número de concluintes nos cursos de Licenciatura em Biologia, Matemática, Física e Química por ano, segundo o tempo até conclusão e tempo médio de conclusão - Brasil 2009 a 2013

\begin{tabular}{|c|c|c|c|c|c|}
\hline \multirow{2}{*}{$\begin{array}{l}\text { Tempo até conclusão } \\
\text { (em anos) }\end{array}$} & \multicolumn{5}{|c|}{ Ano de conclusão } \\
\hline & 2009 & 2010 & 2011 & 2012 & 2013 \\
\hline ATÉ 4 & 65,1 & 55,7 & 48,2 & 45,8 & 44,2 \\
\hline 5 & 20,2 & 27,3 & 27,9 & 28,4 & 27,2 \\
\hline 6 & 7,5 & 9,2 & 14,5 & 14,7 & 14,9 \\
\hline 7 & 3,4 & 4,1 & 4,7 & 5,8 & 7,7 \\
\hline 8 OU MAIS & 3,8 & 3,8 & 4,7 & 5,3 & 6,0 \\
\hline TOTAL (\%) & 100,0 & 100,0 & 100,0 & 100,0 & 100,0 \\
\hline TOTAL (ABSOLUTO) & 39.850 & 34.356 & 32.428 & 29.461 & 27.065 \\
\hline TEMPO MÉDIO DE CONCLUSÃO & 4,61 & 4,73 & 4,90 & 4,96 & 5,04 \\
\hline
\end{tabular}

Fonte: Inep, Microdados do Censo da Educação Superior 2009 a 2013.

A comparação da distribuição do número de concluintes segundo o tempo de curso (em anos simples) sob a ótica transversal (concluintes em cada ano) e sob a ótica geracional da coorte de ingressos de 2009 dos cursos de Biologia, Matemática, Física e Química está representada para cada disciplina no Gráfico 1 (painéis A a D). Essas distribuições do número de concluintes apresentam um comportamento
6 Deve-se lembrar que a distribuição desde a ótica transversal informa a trajetória de maneira retrospectiva e. portanto, somente inclui alunos que estavam ativos no respectivo ano (as perdas ao longo do tempo não são consideradas). 
de crescimento até um ponto $t$ seguido de uma redução na velocidade de crescimento. Em todos os cursos, verifica-se um aumento no tempo de conclusão ao longo do período de 2009 a 2013, assim como observado para o total (Tabela 3).

GRÁFICO 1 - Distribuição do número de concluintes sob as óticas transversal (em 2009, 2010, 2011 e 2013) e geracional (ingressos em 2009) segundo o tempo (em anos) até conclusão dos cursos de Licenciatura em Bioloqia. Matemática. Física e Química - Brasil

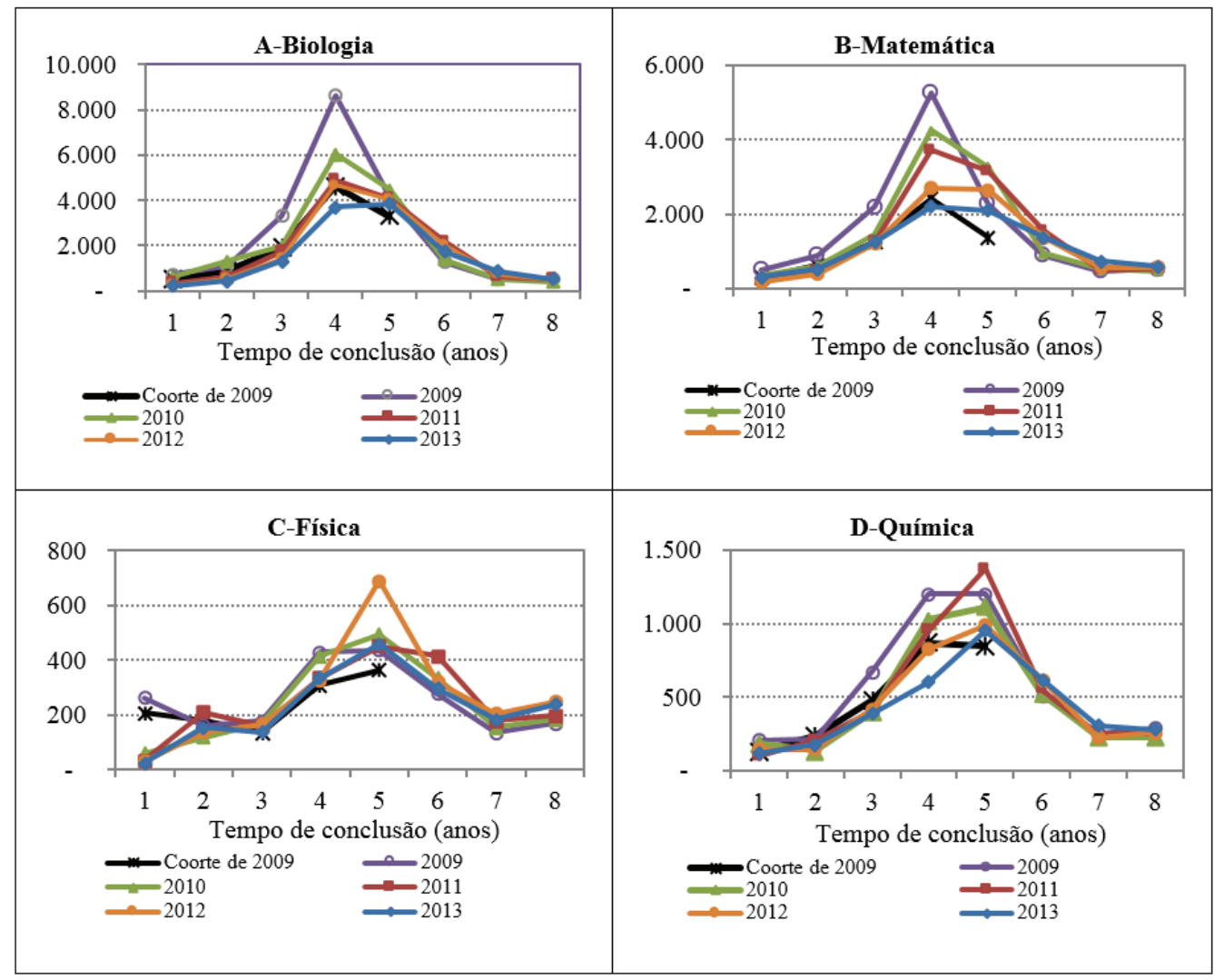

Fonte: Inep, Microdados do Censo da Educação Superior 2009 a 2013.

Nota: A série de ingressos em 2009 somente foi acompanhada até 2013; por isso, encontra-se incompleta.

Enquanto, nos cursos de Biologia e Matemática, a maior parte dos alunos concluiu o curso em quatro anos, nos cursos de Física e Química, a conclusão ocorreu predominantemente no quinto ano de curso. No entanto, já é possível notar uma tendência de maior equilíbrio do número de concluintes entre o quarto e o quinto anos nos cursos de Biologia e Matemática nos anos mais recentes (2011 a 2013), o que 
aponta na mesma direção do comportamento observado em Física e Química de 2009 para 2010, ou seja, de passagem da predominância de concluintes para o quinto ano de curso.

Após a análise do tempo médio de conclusão nos cursos, procedeu-se ao cálculo do percentual de concluintes segundo tempo de curso para a série histórica completa (oito anos), estimando-se o somatório dos percentuais de concluintes em relação ao número de ingressantes ano a ano. Para melhor entendimento dessa análise, foi construído o Diagrama 1 com os dados de período, ano 2013, referente à disciplina de Biologia, o qual representa a análise retrospectiva de conclusão de coortes sintéticas. O tempo de curso em anos é calculado a partir da variável data de ingresso no curso (disponível para todos os alunos no ano 2013), a qual, quando associada à situação de vínculo do aluno no curso, permite distribuir o número de concluintes por tempo de curso. Assim, dos 12.638 concluintes em 2013 do curso de Biologia (soma da diagonal do Diagrama 1), 516 ingressaram no ano 2006 (oito anos de curso), 837 ingressaram em 2007 (sete anos de curso), e assim por diante.

DIAGRAMA 1 - Cálculo do percentual acumulado de concluintes (soma da diagonal) distribuídos segundo o ano de ingresso e tempo de curso (em anos), Curso de Biologia - Brasil - 2013

\begin{tabular}{|c|c|c|c|c|c|c|c|c|}
\hline \multirow{2}{*}{$\begin{array}{c}\text { TEMPO DE CONCLUSÃO } \\
\text { (ANOS) }\end{array}$} & \multicolumn{8}{|c|}{ ANO DE INGRESSO } \\
\hline & 2006 & 2007 & 2008 & 2009 & 2010 & 2011 & 2012 & 2013 \\
\hline 1 & & & & & & & & 234 \\
\hline 2 & & & & & & & 452 & \\
\hline 3 & & & & & & 1.329 & & \\
\hline 4 & & & & & 3.700 & & & \\
\hline 5 & & & & 3.839 & & & & \\
\hline 6 & & & 1.731 & & & & & \\
\hline 7 & & 837 & & & & & & \\
\hline 8 & 516 & & & & & & & \\
\hline INGRESSOS NO ANO & 41.511 & 40.607 & 36.273 & 34.329 & 30.658 & 26.657 & 28.991 & 26.842 \\
\hline \% ANUAL DE CONCLUSÃO & 1,2 & 2,1 & 4,8 & 11,2 & 12,1 & 5,0 & 1,6 & 0,9 \\
\hline $\begin{array}{l}\text { \% ACUMULADA DE } \\
\text { CONCLUINTES }\end{array}$ & 1,2 & 3,3 & 8,1 & 19,3 & 31,3 & 36,3 & 37,9 & 38,7 \\
\hline
\end{tabular}

Fonte: Inep, Microdados do Censo da Educação Superior 2006 a 2013. 
A análise representada para 2013 também foi realizada para os anos 2009, 2010, 2011 e 2012 para todos os cursos estudados. Estimou-se a curva de crescimento da taxa de conclusão para a coorte de 2009 admitindo-se como limite superior à média dos percentuais acumulados de conclusão observados nos anos 2009, 2010, 2011, 2012 e 2013, conforme representados no Gráfico 2. Observa-se que essa distribuição apresenta um crescimento exponencial até um ponto $t$, seguido de uma desaceleração que coincide com uma função de crescimento logístico a partir de um primeiro nível até uma assíntota superior.

GRÁFICO 2 - Distribuições das médias do percentual de concluintes em relação ao número de ingressos sob a ótica transversal para os cursos de Licenciatura em Biologia, Matemática, Física e Química Brasil - 2009 a 2013

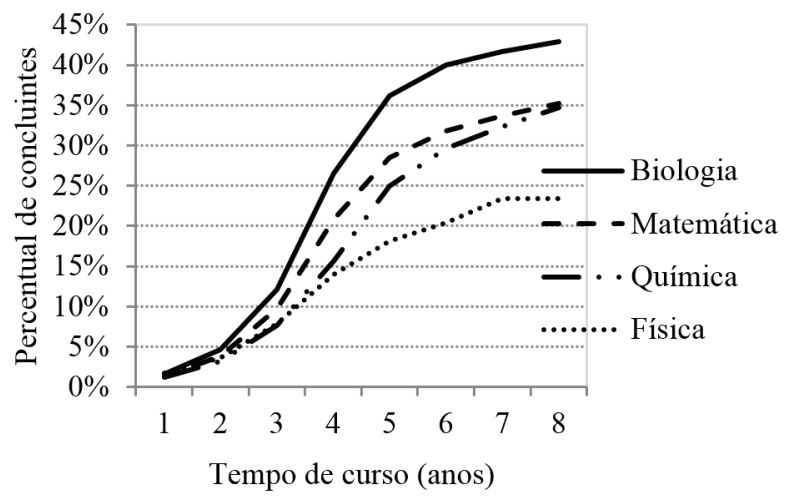

Fonte: Inep, Microdados do Censo da Educação Superior 2009 a 2013

Os coeficientes da estimação da equação de crescimento logístico de cada disciplina estudada com os resultados encontrados para a taxa de conclusão dos alunos que ingressaram em 2009 estão apresentados na Tabela 4, em que se verificam ajustes com boa qualidade para todos os cursos. 
TABELA 4 - Síntese do resultado (coeficientes) dos ajustes das curvas de crescimento logístico das taxas de conclusão em até oito anos, para alunos que ingressaram em 2009, nos cursos de Licenciatura em Biologia, Matemática, Física e Química - Brasill

\begin{tabular}{c|c|c|c}
\hline cuRso & CONSTANTE & $\boldsymbol{\beta}$ & $\mathbf{R}^{\mathbf{2}}$ \\
\hline Biologia & 223,442 & 0,318 & 0,998 \\
\hline Matemática & 219,498 & 0,367 & 0,987 \\
\hline Física & 69,786 & 0,544 & 0,992 \\
\hline Química & 218,649 & 0,381 & 0,998 \\
\hline
\end{tabular}

Fonte: Inep, Microdados do Censo da Educação Superior 2013.

As curvas estimadas para todos os cursos estão representadas no Gráfico 3, a partir dos dados observados nos primeiros cinco anos (estudo geracional da coorte real) e da estimação dos demais pontos do tempo não observados (2014, 2015 e 2016)..$^{7}$ Conforme verificado no estudo longitudinal da trajetória escolar, uma característica importante do fenômeno da conclusão de curso é que esta ocorre a partir do primeiro ano de curso; assim, cada coorte de ingressos registrada anualmente pelo Censo da Educação Superior fornecerá ao mercado de trabalho concluintes do primeiro ao oitavo ano de curso. As estimativas encontradas para a taxa de conclusão em até oito anos daqueles que ingressaram em 2009 nos cursos estudados foram: 42,57\% em Biologia, 34,14\% em Matemática, 20,46\% em Física e 33,86\% em Química. Essas estimativas são bastante baixas, considerando-se a possível eficiência do sistema educacional, ou seja, entre todos aqueles que ingressaram em 2009 nos cursos analisados, nem a metade concluiu o curso, sendo que Física teve o pior desempenho, com apenas $1 / 4$ (um quarto) de conclusão. Vale ressaltar que parte da não conclusão ocorre devido à mudança de cursos. No entanto, fica patente a perda de recursos financeiros e humanos no atual sistema educacional de formação de professores no país.
7 Os resultados foram obtidos utilizando-se o software estatístico Statistical Package for the Social Sciences (SPSS) 
GRÁFICO 3 - Estimação da taxa de conclusão dos ingressos de 2009 dos cursos de Biologia, Matemática, Física e Química - Brasil - 2013
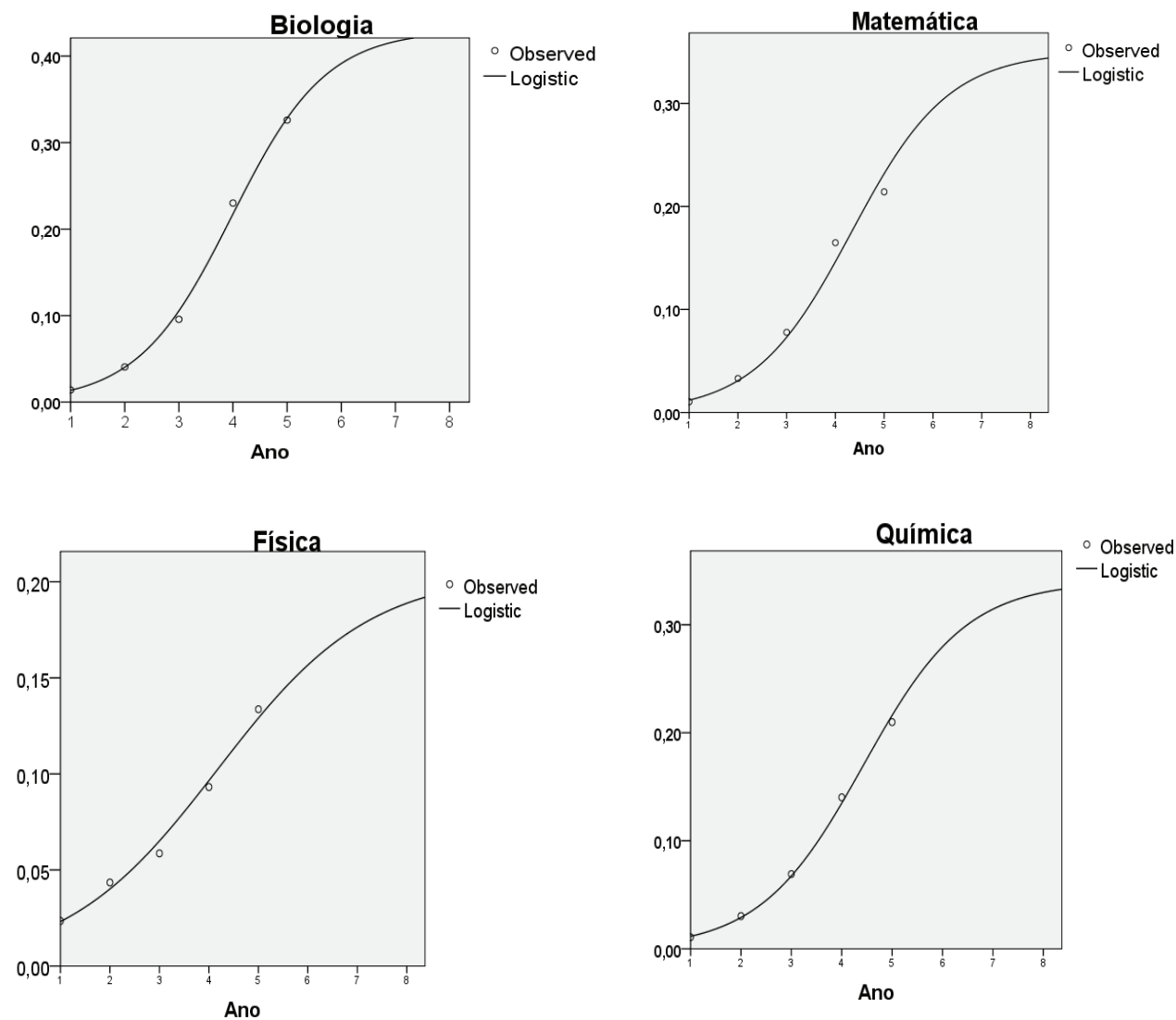

Fonte: Inep, Microdados do Censo da Educação Superior 2013

A média nacional da taxa de conclusão por curso não alcança a diversidade de resultados que ocorrem no país, dentre outros motivos, devido à heterogeneirade regional $\mathrm{e}$ às características das instituições de ensino. Assim, calcularam-se as taxas de conclusão por modalidade de ensino e categoria administrativa para cada disciplina, mostradas no Gráfico 4. Os resultados evidenciam que os cursos presenciais possuem taxas de conclusão bem maiores do que os cursos a distância, com exceção do curso de Química na rede privada. Destaca-se que a taxa de conclusão na rede privada é maior que na pública, nas duas modalidades de ensino, em todos os cursos estudados. Esse resultado merece estudos posteriores para a devida compreensão, já que pode ser uma 
especificidade dos cursos de formação de professores.

Importante ressaltar que a rede privada, além de ter maiores taxas de conclusão, representa a maior proporção dos ingressos de 2009 no curso de Licenciatura em Biologia, visto que $56,5 \%$ destes ingressaram na rede privada. Nos demais cursos, apesar das piores taxas de conclusão no ensino público, este é responsável pela maioria dos ingressos de 2009, com 88,5\% no curso de Física, 63,2\% de Matemática e de $69,6 \%$ no de Química. Esses dados e a composição completa dos ingressos de 2009 segundo a modalidade de ensino e tipo de rede estão apresentados no Apêndice 2 .

GRÁFICO 4 - Taxa de conclusão por modalidade de ensino nos cursos de Licenciatura em Biologia, Matemática, Física e Química, segundo rede de ensino dos ingressos de 2009 - Brasil

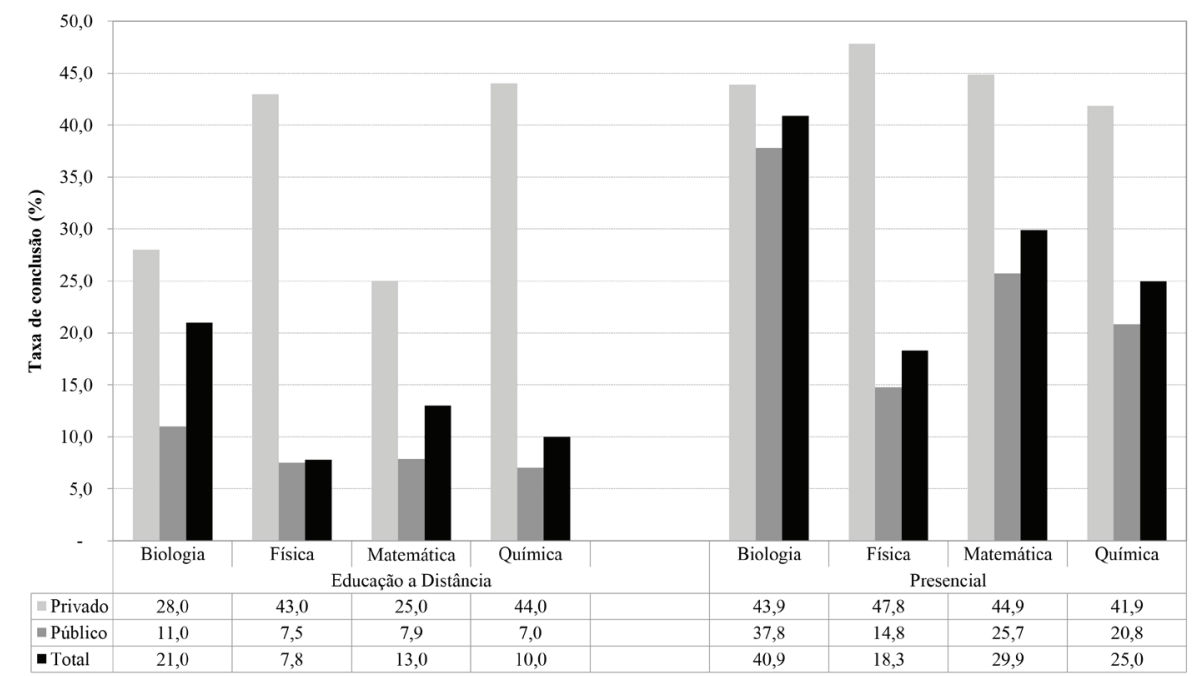

Fonte: Inep, Microdados do Censo da Educação Superior 2009 a 2013.

INDICADORES DE RETENÇÃO DE DOCENTES NA SALA DE AULA

$O$ estudo longitudinal dos docentes foi realizado a partir do pareamento da variável ID_DOCENTE ano a ano, no período de 2009 a 2013. Essa análise identificou um percentual relevante de saídas com retorno, ou seja, profissionais que estavam em sala de aula em um ano $t$, mas não se encontravam em sala de aula no ano $t+n$ e retornam em $t+n+1$ (Figura 1).

A Figura 1 demonstra a trajetória profissional dos docentes que atuaram em sala de aula nas disciplinas estudadas entre 
2009 e 2013. A linha contínua representa o tempo que o professor permaneceu sem afastamento da sala de aula, enquanto a linha pontilhada refere-se ao tempo afastado da sala de aula. Para análise da trajetória profissional dos docentes, a linha pontilhada, que representa uma saída com retorno, foi atribuída apenas para os casos observados em que o docente voltou para sala de aula em até quatro anos depois do primeiro vínculo registrado em sala de aula. Os casos de descontinuidade do vínculo (representados por $x$ ) podem futuramente ser uma saída com retorno, mas serão tratados como uma saída definitiva do sistema de ensino, visto que, durante o período observado, não houve registro de retorno à sala de aula.

O quantitativo expresso ano a ano é composto de novas entradas, retorno de profissionais que estiveram fora da sala de aula por algum motivo e saídas definitivas da regência da disciplina. Permaneceram continuamente (sem afastamentos da sala de aula) no quinquênio: $34 \%$ (97.396) dos docentes que estavam em sala de aula em 2009 na disciplina de Matemática, 34\% (17.120) na disciplina de Biologia, 35\% (15.937) na disciplina de Química e 30\% (15.273) na disciplina de Física.

Ao considerar como saídas definitivas do sistema de ensino os casos representados com $o x$ na Figura 1, foram contabilizados: $47 \%$ dos docentes de Matemática, $49 \%$ de Biologia, $51 \%$ de Física e $49 \%$ de Química. No entanto, a identificação de relevante percentual de saídas com retorno na regência de sala de aula dificulta a mensuração do turnover no mercado de trabalho docente. Apenas para o período analisado, foram contabilizados, de 2009 a 2013, nessa situação (casos identificados pelas linhas pontilhadas): 19\% dos docentes de Matemática e Física, 17\% dos docentes de Biologia e 16\% dos docentes de Química. 
FIGURA 1 - Trajetória profissional dos docentes com regência na disciplina de Matemática, Biologia, Física e Química - Brasil - 2009 a 2013

MATEMÁTICA

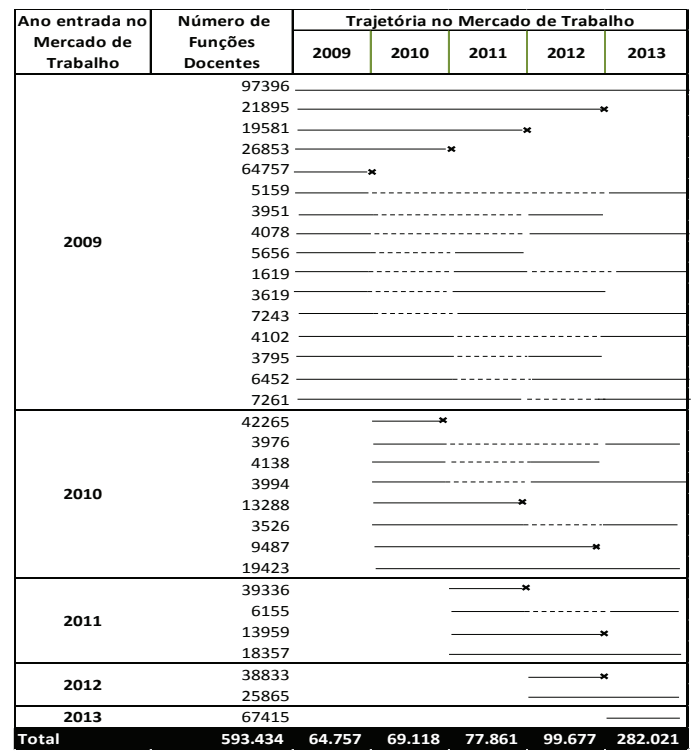

FÍSICA

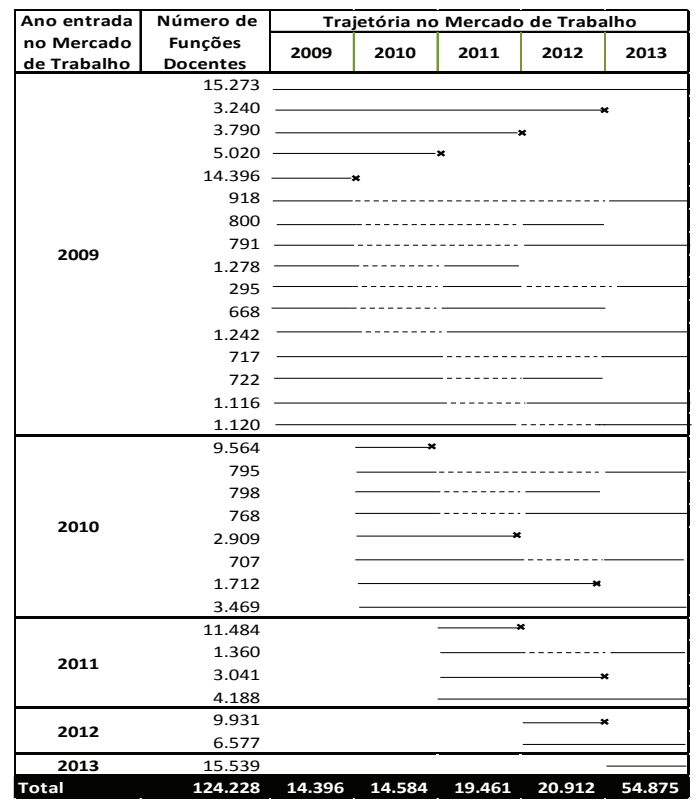

BIOLOGIA

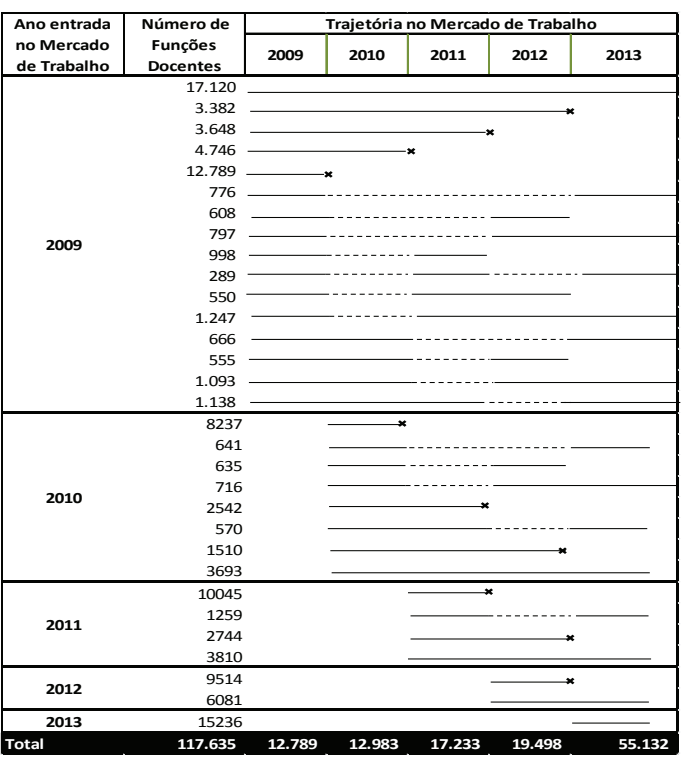

QUÍMICA

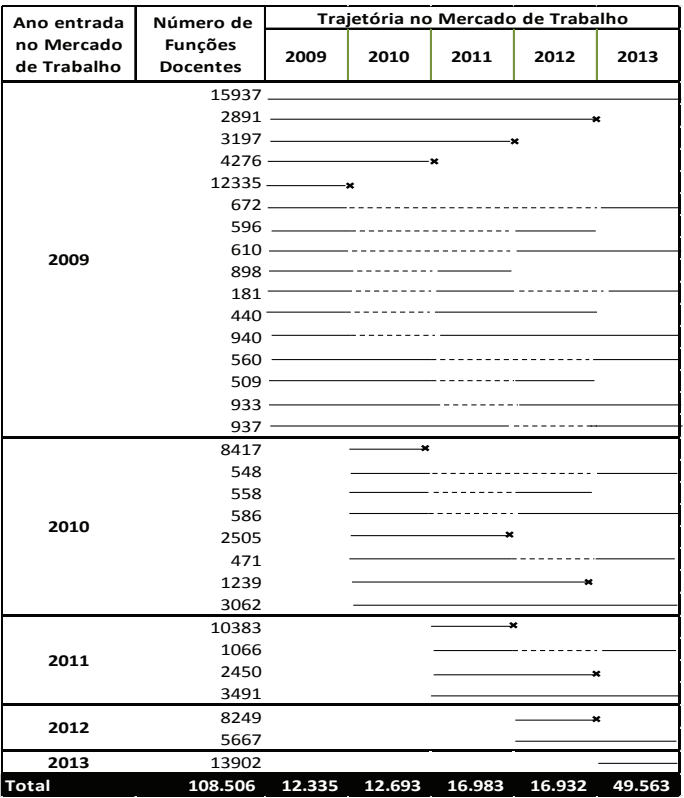

Fonte: Inep, Microdados do Censo da Educação Superior 2009 e 2013. 
Sob uma segunda ótica, o percentual de permanência no sistema de ensino foi observado a partir da comparação entre o estoque anual de docentes por disciplina e o estoque de docentes no quinquênio 2009 a 2013. Importante esclarecer que o total de docentes do quinquênio foi calculado pelo acompanhamento longitudinal da variável ID_DOCENTE (variável controle). Assim, o estoque anual de docentes representa, em relação ao estoque quinquenal, o saldo quinquenal de entradas e saídas do mercado de trabalho em cada ano (Tabela 5). Observa-se que o estoque anual de docentes nas disciplinas estudadas corresponde a menos da metade do total de vínculos registrados no período de 2009 a 2013, ou seja, assumindo uma mortalidade dos docentes igual a zero durante os cinco anos estudados, menos da metade dos docentes permanecem em sala de aula atuando na mesma disciplina.

TABELA 5 - Estimativa de permanência dos docentes de Matemática, Biologia, Física e Química no sistema de ensino (ensino médio e anos finais do ensino fundamental) - Brasil - 2009 a 2013

\begin{tabular}{c|c|c|c|c|c|c|c|c}
\hline \multirow{2}{*}{ ANO } & \multicolumn{2}{|c|}{ BIOLOGIA } & \multicolumn{2}{c|}{ MATEMÁTICA } & \multicolumn{2}{c}{ FÍSICA } & \multicolumn{2}{c}{ QUÍMICA } \\
\cline { 2 - 11 } & $\begin{array}{c}\text { NÚMERO } \\
\text { DE } \\
\text { DOCENTES }\end{array}$ & $\begin{array}{c}\text { \% ANUAL DE } \\
\text { DOCENTES } \\
\text { NO } \\
\text { QUINQUENIO }\end{array}$ & $\begin{array}{c}\text { NÚMERO } \\
\text { DE } \\
\text { DOCENTES }\end{array}$ & $\begin{array}{c}\text { \% ANUAL DE } \\
\text { DOCENTES } \\
\text { NO } \\
\text { QUINQUENIO }\end{array}$ & $\begin{array}{c}\text { NÚMERO } \\
\text { DE } \\
\text { DOCENTES }\end{array}$ & $\begin{array}{c}\text { \% ANUAL DE } \\
\text { DOCENTES } \\
\text { NO } \\
\text { QUINQUENIO }\end{array}$ & $\begin{array}{c}\text { NÚMERO } \\
\text { DE } \\
\text { DOCENTES } \\
\text { \% ANUAL DE } \\
\text { DOCENTES } \\
\text { NO } \\
\text { QUINQUENNIO }\end{array}$ \\
\hline $\mathbf{2 0 0 9}$ & 50.402 & 42,8 & 283.417 & 47,8 & 51.386 & 41,4 & 45.912 & 42,3 \\
\hline $\mathbf{2 0 1 0}$ & 50.892 & 43,3 & 287.432 & 48,4 & 51.720 & 41,6 & 46.626 & 43 \\
\hline $\mathbf{2 0 1 1}$ & 54.545 & 46,4 & 287.801 & 48,5 & 55.776 & 44,9 & 50.088 & 46,2 \\
\hline $\mathbf{2 0 1 2}$ & 54.055 & 45,9 & 282.485 & 47,6 & 54.336 & 43,7 & 48.158 & 44,4 \\
\hline $\mathbf{2 0 1 3}$ & 55.132 & 46,9 & 282.021 & 47,5 & 54.875 & 44,2 & 49.563 & 45,7 \\
\hline Total & 117.635 & $100,0 \%$ & 593.434 & $100,0 \%$ & 124.228 & $100,0 \%$ & 108.506 & $100,0 \%$ \\
\hline
\end{tabular}

Fonte: Inep, Microdados do Censo da Educação Superior 2009 e 2013.

Segundo os resultados dos estudos longitudinais dos docentes, o percentual de retenção anual desses profissionais em sala de aula é inferior a 50\%. De acordo com a definição do acompanhamento do código de identificação do docente durante os anos analisados (2009 a 2013), permaneceram continuamente (sem afastamentos da sala de aula) no quinquênio: $34 \%$ (97.396) dos docentes que estavam em sala de aula em 2009 na disciplina de Matemática, 34\% (17.120) na de Biologia, 35\% (15.937), na de Química e 30\% (15.273) na de Física. 


\section{CONSIDERAÇÕES FINAIS}

$\mathrm{O}$ atendimento escolar no Brasil tem apresentado significativos avanços nos últimos anos, visto o aumento da cobertura do ensino fundamental e, até certo ponto, do ensino médio. No entanto, a qualidade do ensino brasileiro vem sendo apontada como um problema na formação dos alunos. A disponibilidade de profissionais com formação adequada para o ensino fundamental e médio destaca-se como peça importante para aumentar a qualidade do ensino.

$\mathrm{O}$ potencial de análise longitudinal das informações discentes do Censo da Educação Superior e de docentes do Censo da Educação Básica explorados neste artigo permitiu mapear as trajetórias escolares dos alunos e profissionais docentes e propor, a partir destas, o cálculo de indicadores que subsidiam a discussão acerca da formação de docentes. Os resultados encontrados apontam para uma dificuldade crescente de oferta de docentes para atendimento do sistema de ensino brasileiro para as disciplinas específicas (Matemática, Física, Biologia e Química), visto o baixo desempenho dos indicadores aqui estimados.

As taxas de conclusão dos cursos de licenciatura são baixíssimas considerando os ingressantes em 2009: em Biologia, de 42,6\%; em Matemática, de 34,1\%; em Física, de 20,5\%; e em Química, de 33,9\%. Apesar do esforço para o aumento do número de vagas nos cursos de licenciatura, pode-se afirmar que o desperdício de recursos humanos e financeiros é enorme, já que nem 50\% dos alunos ingressantes se graduaram no final do período. Esses resultados se tornam ainda mais preocupantes quando os dados nacionais são desagregados por rede e modalidade de ensino dos cursos. Os cursos a distância ainda apresentam baixíssimas taxas de conclusão. Adicionalmente, a rede pública tem taxas de conclusão abaixo daquelas da rede privada. Tais resultados precisam ser avaliados para outros cursos, para se determinar se são particularidades daqueles analisados aqui, ou seja, os de licenciatura, ou se poderiam ser generalizados para todo o ensino superior. Outro indicador estimado a partir da trajetória dos alunos da coorte de 2009 chama bastante atenção. Além das baixas taxas de conclusão, ainda apresenta a tendência 
de aumento no tempo médio de conclusão dos cursos. Essa taxa cresce de 4,61 anos em 2009 para 5,04 em 2013 (considerando os quatro cursos estudados conjuntamente). $\mathrm{Ou}$ seja, além de haver baixa conclusão, os alunos têm demorado mais para se formarem.

A análise da trajetória dos docentes em sala de aula aponta para um problema ainda maior, visto que o percentual de retenção anual desses docentes em sala de aula é inferior a $50 \%$. Portanto, tampouco resolve somente graduar professores com a formação adequada; são necessárias medidas para a retenção dos docentes em sala, num esforço conjunto entre as áreas de educação e o mercado de trabalho. Ainda, deve-se lembrar que a análise realizada somente considerou professores em sala de aula no quinquênio 2009 a 2013 e não todos os profissionais formados nas disciplinas analisadas, o que aumenta sobremaneira a porcentagem de docentes que não exercem suas funções em salas de aula.

O desempenho desfavorável desse conjunto de indicadores corrobora a discussão acerca da escassez desses profissionais no mercado de trabalho. $\mathrm{O}$ incremento do número de vagas para formação de novos professores acaba sofrendo os efeitos da baixa taxa de conclusão, do aumento do tempo de conclusão dos cursos e da baixa permanência de docentes na regência das disciplinas estudadas de um ano para outro. A desagregação desses indicadores para áreas geográficas e outras desagregações poderão ajudar no diagnóstico mais detalhado desse problema, em busca de possíveis medidas e políticas públicas que possam de fato trazer soluções efetivas e eficientes.

O presente estudo pode ser ampliado para todas as demais disciplinas específicas dos anos finais do ensino fundamental e ensino médio. Os indicadores de conclusão também podem ser aferidos para os demais cursos de graduação, abrangendo outras profissões de nível superior. 


\section{REFERÊNCIAS}

BRASIL. Conselho Nacional de Educação. Escassez de professores no ensino médio: propostas estruturais e emergenciais. Brasília, DF: CNE/MEC, maio 2007. Disponível em: <http://portal.mec.gov.br/cne/arquivos/pdf/escassez1.pdf>. Acesso em: 30 jun. 2016.

BRASIL. Escola Nacional de Administração Pública - Enap. Ações premiadas no $15^{\circ}$ Concurso Inovação na Gestão Pública Federal. Enap, 2010. Disponível em: $<$ http://www.enap.gov.br/documents/586010/603804/livro_15.pdf/a57f7a20c6de-493b-ae33-b4c85b23ae11>. Acesso em: 30 jun. 2016.

BRASIL. Lei 13.005, de 25 de junho de 2014. Aprova o Plano Nacional de Educação-PNE e dá outras providências. Diário Oficial da União, Brasília, DF, 26 jun. 2014. Seção 1. Disponível em: <http://www.planalto.gov.br/ ccivil_03/_Ato2011-2014/2014/Lei/L13005.htm>. Acesso em: 15 nov. 2015.

BRASIL. Instituto Nacional de Estudos e Pesquisas Educacionais Anísio Teixeira. Manual de classificação: áreas de formação e treinamento. Brasília, DF: Inep, 2001. Disponível em: <http://download.inep.gov.br/download/ superior/2009/Tabela_OCDE_2009.pdf >. Acesso em: 4 mar. 2014.

BRASIL. Instituto Nacional de Estudos e Pesquisas Educacionais Anísio Teixeira. Estudo exploratório sobre o professor brasileiro. Brasília, DF: Inep, 2009. Disponível em: <http://download.inep.gov.br/download/censo/2009/ Estudo_Professor_1.pdf>. Acesso em: 15 jan. 2014.

BRASIL. Instituto Nacional de Estudos e Pesquisas Educacionais Anísio Teixeira. Censo da educação superior 2009: resumo técnico. Brasília, DF: Inep, 2010. Disponível em: <http://download.inep.gov.br/educacao_superior/ censo_superior/resumo_tecnico/resumo_tecnico_censo_educacao_ superior_2009.pdf>. Acesso em: 9 out. 2012.

BRASIL. Instituto Nacional de Estudos e Pesquisas Educacionais Anísio Teixeira. Censo da educação superior 2010: resumo técnico. Brasília, DF: Inep, 2012. Disponível em: <http://download.inep.gov.br/educacao_superior/ censo_superior/resumo_tecnico/resumo_ 113 tecnico_censo_educacao_ superior_2010.pdf>. Acesso em: 9 out. 2012.

BRASIL. Instituto Nacional de Estudos e Pesquisas Educacionais Anísio Teixeira. Censo escolar 2013: perfil da docência no ensino médio regular. Brasília, DF: Inep, 2015. 110 p.: il.

BRASIL. Ministério da Educação. Portaria MEC n. 316, de 4 de abril de 2007.

FLETCHER, P. As dimensões transversal e longitudinal do modelo Profluxo. Rio de Janeiro: Ministério da Educação e Cultura, 1997.

FLETCHER, P.; RIBEIRO, S. Modeling education system performance with demographic data: an introduction to the Profluxo model. In: BARRETO, E.; ZIBAS, D. (Org.). Brazilian issues on education, gender and race. São Paulo: Fundação Carlos Chagas, 1996.

GOLGHER, A. B. Modelo Profluxo e indicadores derivados. In: RIOS-NETO, E. (Org.). Introdução à Demografia da Educação. Campinas, SP: Abep, 2004. 
KLEIN, R. Algumas dimensões da avaliação da educação superior. In: OLIVEIRA, F. B. de (Org.). Desafios da educação: contribuições estratégicas para o ensino superior. Rio de Janeiro: Fundação Getúlio Vargas, 2009.

NASCIMENTO, P. A. M. M.; SILVA, C. A.; SILVA, P. H. D. da. Subsídios e proposições preliminares para um debate sobre o magistério da educação básica no Brasil. Radar: tecnologia, produção e comércio exterior, Brasília, DF, n. 32, p. 37-51, 2014.

\section{ORGANIZACIÓN DE LAS NACIONES UNIDAS PARA LA EDUCACIÓN, LA}

CIENCIA E LA CULTURAA - UNESCO. Clasificación Internacional Normalizada de la Educación: CINE 1997. Reedição. Unesco, 2006. Disponível em: <http://www.uis. unesco.org/Library/Documents/isced97-es.pdf>. Acesso em: 3 jan. 2015.

PEREIRA, R. H. M.; NASCIMENTO, P. A. M. M.; ARAÚJO, T. C. Projeções de mão de obra qualificada no Brasil: cenários para a disponibilidade de engenheiros até 2020. Revista Brasileira de Estudos Populacionais, Rio de Janeiro, v. 30, n. 2, p. 519-548, jul./dez. 2013.

PINTO, J. M. de R. Falta interesse por carreira de professor, indica estudo. Revista Digital, 3 set. 2014. Disponível em: <http://www.revistadigital.com. br/2014/09/falta-interesse-por-carreira-de-professor-indica-estudo/>. Acesso em: 30 jun. 2016.

RABELO, R. P. Projeção da oferta de professores de matemática, física, química e biologia para educação básica no Brasil até 2028. 2015. Dissertação (Mestrado) Escola Nacional de Estatística, Rio de Janeiro, 2015.

RIGOTTI, J. I. R.; HADAD, R. M. Graduation tables: a proposal for a demographic analysis of educational indicators in Brazil. Belo Horizonte: UFMG, Cedeplar, 2001.

RIOS-NETO, E. L. G. O método probabilidade de progressão por série. In: RIOS-NETO, E. L. G.; RIANI, J. de L. R. (Org.). Introdução à demografia da educação. Campinas, SP: Abep, 2004. p. 143-145.

RUIZ, A. I. Formação continuada e em áreas específicas: a proposta do Sistema Nacional Público. Revista Retratos da Escola, Brasília, DF, v. 2, n. 2-3, p. 149-160, jan./dez. 2008.

SAMPAIO, C. E. M. et al. Estatísticas dos professores no Brasil. Revista Brasileira de Estudos Pedagógicos, Brasília, DF, v. 83, n. 203/204/205, p. 85-120, jan./dez. 2002.

SCHWARTZMAN, S. A educação de nível superior no Censo 2010. Instituto de Estudos do Trabalho e Sociedade, 2012. Disponível em: <http://www. schwartzman.org.br/simon/2012censosup.pdf >. Acesso em: 2 out. 2012. 
RACHEL PEREIRA RABELO

Mestre em Estudos Populacionais e Pesquisas Sociais pela Escola Nacional de Ciências Estatísticas do Instituto Brasileiro de Geografia e Estatística (Ence/IBGE), Rio de Janeiro, Rio de Janeiro, Brasil. Pesquisadora tecnologista em Informações e Avaliações Educacionais do Instituto Nacional de Estudos e Pesquisas Anísio Teixeira (Inep), Brasília, Distrito Federal, Brasil

rachel.rabelo@hotmail.com.br

\section{SUZANA MARTA CAVENAGHI}

Professora e pesquisadora da Escola Nacional de Ciências Estatísticas do Instituto Brasileiro de Geografia e Estatística (Ence/IBGE), Rio de Janeiro, Rio de Janeiro, Brasil suzana.cavenaghi@uol.com.br 


\section{ANEXOS}

APÊNDICE 1 - Mapeamento das trajetórias escolares de 2009 a 2013 dos alunos que ingressaram no ensino superior no ano 2009

\begin{tabular}{|c|c|c|c|c|c|}
\hline $\begin{array}{l}\text { TIPOS DE } \\
\text { TRAJETÓRIA }\end{array}$ & 2009 & 2010 & 2011 & 2012 & 2013 \\
\hline \multirow{4}{*}{$\begin{array}{l}1 \text { - Vinculo final } \\
\text { indeterminado }\end{array}$} & PF, C, MT, D, Fal & C, MT, D, Fal & C, MT, D, Fal & C, MT, D, Fal & $\mathrm{C}, \mathrm{MT}$ \\
\hline & PF, C, MT, D, Fal & $\mathrm{TC}$ & C, MT, D, TC, Fal & C, MT, D,TC, Fal & C, MT \\
\hline & PF, C, MT, D, Fal & C, MT, D,TC, Fal & $\mathrm{TC}$ & C, MT, D, TC, Fal & C, MT \\
\hline & PF, C, MT, D, Fal & C, MT, D,TC, Fal & C, MT, D,TC, Fal & TC & C, MT \\
\hline \multirow{5}{*}{$\begin{array}{l}2.1 \text { - Conclusão } \\
\text { "ideal" }\end{array}$} & $\mathrm{F}$ & SV & SV & SV & SV \\
\hline & PF, C, MT & $\mathrm{F}$ & SV & SV & SV \\
\hline & PF, C, MT & $\mathrm{C}, \mathrm{MT}$ & $\mathrm{F}$ & SV & SV \\
\hline & $\mathrm{PF}, \mathrm{C}, \mathrm{MT}$ & C, MT & $\mathrm{C}, \mathrm{MT}$ & $\mathrm{F}$ & SV \\
\hline & $\mathrm{PF}, \mathrm{C}, \mathrm{MT}$ & $\mathrm{C}, \mathrm{MT}$ & $\mathrm{C}, \mathrm{MT}$ & $\mathrm{C}, \mathrm{MT}$ & $\mathrm{F}$ \\
\hline \multirow{4}{*}{$\begin{array}{l}2.2 \text { - Conclusão } \\
\text { com trajetória } \\
\text { inconsistente }\end{array}$} & $\mathrm{D}, \mathrm{Fal}$ & $F$ & SV & SV & SV \\
\hline & D, Fal & C, MT, TC, D, Fal & $F$ & SV & SV \\
\hline & D, Fal & C, MT, TC, D, Fal & C, MT, TC, D, Fal & $\mathrm{F}$ & SV \\
\hline & $\mathrm{D}, \mathrm{Fal}$ & C, MT, TC, D, Fal & C, MT, TC, D, Fal & C, MT, TC, D, Fal & $\mathrm{F}$ \\
\hline \multirow{26}{*}{$\begin{array}{l}2.3 \text { - Conclusão } \\
\text { imprecisa }\end{array}$} & $F$ & SV & SV & SV & C, MT, TC, D, F, Fal \\
\hline & $\mathrm{F}$ & SV & SV & C, MT, TC, D, F, Fal & C, MT, TC, D, F, Fal \\
\hline & $\mathrm{F}$ & SV & C, MT, TC, D, F, Fal & C, MT, TC, D, F, Fal & C, MT, TC, D, F, Fal \\
\hline & $\mathrm{F}$ & C, MT, TC, D, F, Fal & SV & SV & SV \\
\hline & $\mathrm{F}$ & C, MT, TC, D, F, Fal & C, MT, TC, D, F, Fal & SV & SV \\
\hline & $\mathrm{F}$ & C, MT, TC, D, F, Fal & C, MT, TC, D, F, Fal & C, MT, TC, D, F, Fal & SV \\
\hline & $\mathrm{F}$ & C, MT, TC, D, F, Fal & C, MT, TC, D, F, Fal & C, MT, TC, D, F, Fal & C, MT, TC, D, F, Fal \\
\hline & $\mathrm{F}$ & SV & C, MT, TC, D, F, Fal & SV & C, MT, TC, D, F, Fal \\
\hline & $\mathrm{F}$ & SV & SV & C, MT, TC, D, F, Fal & SV \\
\hline & $\mathrm{F}$ & SV & C, MT, TC, D, F, Fal & C, MT, TC, D, F, Fal & SV \\
\hline & $\mathrm{F}$ & SV & C, MT, TC, D, F, Fal & SV & SV \\
\hline & $\mathrm{F}$ & C, MT, TC, D, F, Fal & SV & SV & C, MT, TC, D, F, Fal \\
\hline & $\mathrm{F}$ & C, MT, TC, D, F, Fal & SV & C, MT, TC, D, F, Fal & $\mathrm{C}, \mathrm{MT}, \mathrm{TC}, \mathrm{D}, \mathrm{F}, \mathrm{Fal}$ \\
\hline & $\mathrm{F}$ & C, MT, TC, D, F, Fal & SV & C, MT, TC, D, F, Fal & SV \\
\hline & $\mathrm{F}$ & C,MT, TC, D, F, Fal & $\begin{array}{c}\mathrm{C}, \mathrm{MT}, \mathrm{TC}, \mathrm{D}, \mathrm{F}, \\
\mathrm{Fal}\end{array}$ & SV & $\begin{array}{c}\mathrm{C}, \mathrm{MT}, \mathrm{TC}, \mathrm{D}, \mathrm{F}, \\
\mathrm{Fal}\end{array}$ \\
\hline & PF, C, MT, D, Fal & $F$ & C, MT, TC, D, F, Fal & SV & SV \\
\hline & PF, C, MT, D, Fal & $F$ & C, MT, TC, D, F, Fal & C, MT, TC, D, F, Fal & SV \\
\hline & PF, C, MT, D, Fal & $\mathrm{F}$ & C, MT, TC, D, F, Fal & C, MT, TC, D, F, Fal & C, MT, TC, D, F, Fal \\
\hline & PF, C, MT, D, Fal & $\mathrm{F}$ & SV & SV & C, MT, TC, D, F, Fal \\
\hline & PF, C, MT, D, Fal & $\mathrm{F}$ & SV & C, MT, TC, D, F, Fal & C, MT, TC, D, F, Fal \\
\hline & PF, C, MT, D, Fal & $\mathrm{F}$ & SV & C, MT, TC, D, F, Fal & SV \\
\hline & PF, C, MT, D, Fal & $\mathrm{F}$ & C, MT, TC, D, F, Fal & SV & C, MT, TC, D, F, Fal \\
\hline & PF, C, MT, D, Fal & C, MT, TC, D, Fal & $\mathrm{F}$ & C, MT, TC, D, F, Fal & SV \\
\hline & PF, C, MT, D, Fal & C, MT, TC, D, Fal & $\mathrm{F}$ & C, MT, TC, D, F, Fal & C, MT, TC, D, F, Fal \\
\hline & PF, C, MT, D, Fal & SV & $\mathrm{F}$ & C, MT, TC, D, F, Fal & SV \\
\hline & PF, C, MT, D, Fal & C, MT, TC, D, Fal & C, MT, TC, D, Fal & $\mathrm{F}$ & C, MT, TC, D, F, Fal \\
\hline
\end{tabular}


APÊNDICE 1 - Mapeamento das trajetórias escolares de 2009 a 2013 dos alunos que ingressaram no ensino superior no ano 2009

\begin{tabular}{|c|c|c|c|c|c|}
\hline $\begin{array}{l}\text { TIPOS DE } \\
\text { TRAJETÓRIA }\end{array}$ & 2009 & 2010 & 2011 & 2012 & 2013 \\
\hline \multirow{4}{*}{3 - Perda } & $\mathrm{PF}, \mathrm{C}, \mathrm{MT}$ & SV & SV & SV & SV \\
\hline & PF, C, MT, D & C, MT & SV & SV & SV \\
\hline & PF, C, MT, D & C, MT, TC, D, Fal & C, MT & SV & SV \\
\hline & PF, C, MT, D & C, MT, TC, D, Fal & C, MT, TC, D, Fal & C, MT & SV \\
\hline \multirow{5}{*}{$\begin{array}{l}4 \text { - Não } \\
\text { concluíram }\end{array}$} & D, Fal & SV & SV & SV & SV \\
\hline & $\mathrm{PF}, \mathrm{C}, \mathrm{MT}, \mathrm{D}, \mathrm{Fal}$ & D, Fal & SV & SV & SV \\
\hline & PF, C, MT, D, Fal & C, MT, D, TC, Fal & D, Fal & SV & SV \\
\hline & PF, C, MT, D, Fal & C, MT, D, TC, Fal & C, MT, D, TC, Fal & D, Fal & SV \\
\hline & $\mathrm{PF}, \mathrm{C}, \mathrm{MT}, \mathrm{D}, \mathrm{Fal}$ & C, MT, D, TC, Fal & C, MT, D, TC, Fal & C, MT, D, TC, Fal & $\mathrm{D}, \mathrm{Fal}$ \\
\hline \multirow{4}{*}{$\begin{array}{l}5 \text { - Transferência } \\
\text { de curso }\end{array}$} & PF, C, MT, D, Fal & $\mathrm{TC}$ & SV & SV & SV \\
\hline & PF, C, MT, D, Fal & C, MT, D, TC, Fal & $\mathrm{TC}$ & SV & SV \\
\hline & PF, C, MT, D, Fal & C, MT, D, TC, Fal & C, MT, D, TC, Fal & $\mathrm{TC}$ & SV \\
\hline & PF, C, MT, D, Fal & C, MT, D, TC, Fal & C, MT, D, TC, Fal & C, MT, D, TC, Fal & $\mathrm{TC}$ \\
\hline \multirow{9}{*}{$\begin{array}{l}6 \text { - Perdidos com } \\
\text { retorno }\end{array}$} & PF, C, MT, D, Fal & SV & $\begin{array}{c}\text { C, MT, D, TC, F, } \\
\text { Fal, SV }\end{array}$ & $\begin{array}{c}\text { C, MT, D, TC, F, } \\
\text { Fal, SV }\end{array}$ & $\begin{array}{c}\text { C,MT, D, TC,F, Fal, } \\
\text { SV }\end{array}$ \\
\hline & PF, C, MT, D, Fal & SV & SV & $\begin{array}{c}\text { C, MT, D, TC, F, } \\
\text { Fal, SV }\end{array}$ & $\begin{array}{l}\text { C, MT, D, TC, F, } \\
\text { Fal, SV }\end{array}$ \\
\hline & PF, C, MT, D, Fal & SV & SV & SV & $\begin{array}{c}\text { C, MT, D, TC, F, } \\
\text { Fal, SV }\end{array}$ \\
\hline & PF, C, MT, D, Fal & SV & $\begin{array}{c}\text { C, MT, D, TC, F, } \\
\text { Fal, SV }\end{array}$ & SV & $\begin{array}{c}\text { C, MT, D, TC, F, } \\
\text { Fal, SV }\end{array}$ \\
\hline & PF, C, MT, D, Fal & SV & $\begin{array}{c}\text { C, MT, D, TC, F, } \\
\text { Fal, SV }\end{array}$ & $\begin{array}{c}\text { C, MT, D, TC, F, } \\
\text { Fal, SV }\end{array}$ & SV \\
\hline & PF, C, MT, D, Fal & C, MT, D, TC, Fal, SV & SV & $\begin{array}{c}\text { C, MT, D, TC, F, } \\
\text { Fal, SV }\end{array}$ & $\begin{array}{l}\text { C, MT, D, TC, F, } \\
\text { Fal, SV }\end{array}$ \\
\hline & PF, C, MT, D, Fal & C, MT, D, TC, Fal, SV & SV & SV & $\begin{array}{l}\text { C, MT, D, TC, F, } \\
\text { Fal, SV }\end{array}$ \\
\hline & PF, C, MT, D, Fal & C, MT, D, TC, Fal, SV & SV & $\begin{array}{c}\text { C, MT, D, TC, F, } \\
\text { Fal, SV }\end{array}$ & SV \\
\hline & PF, C, MT, D, Fal & C, MT, D, TC, Fal, SV & $\begin{array}{c}\text { C, MT, D, TC, F, } \\
\text { Fal, SV }\end{array}$ & SV & $\begin{array}{c}\text { C, MT, D, TC, F, } \\
\text { Fal, SV }\end{array}$ \\
\hline
\end{tabular}

Fonte: Elaboração das autoras.

Legenda: $\mathrm{PF}=$ Provável Formando, $\mathrm{C}=$ Cursando, $\mathrm{MT}=$ Matrícula trancada, $\mathrm{D}=$ Desvinculado,

$\mathrm{TC}=$ Transferência de curso na mesma IES, F= Formado, Fal= Falecido, SV= Sem vínculo. 
APÊNDICE 2 - Distribuição percentual de ingressos em 2009 nos cursos de Licenciatura em Biologia, Matemática, Física e Química segundo rede de ensino e modalidades de ensino - Brasil - 2009

\begin{tabular}{|l|c|c|c|c|c|}
\hline $\begin{array}{l}\text { REDE DE ENSINO E } \\
\text { MODALIDADE DE ENSINO }\end{array}$ & BIOLOGIA & MATEMÁTICA & FÍSICA & QUÍMICA & TOTAL \\
\hline Total & $\mathbf{1 0 0 , 0}$ & $\mathbf{1 0 0 , 0}$ & $\mathbf{1 0 0 , 0}$ & $\mathbf{1 0 0 , 0}$ & $\mathbf{1 0 0 , 0}$ \\
\hline Privada & 56,5 & 36,8 & 11,5 & 30,4 & 41,2 \\
\hline Pública & 43,5 & 63,2 & 88,5 & 69,6 & 58,8 \\
\hline Educação a distância & $\mathbf{2 3 , 3}$ & $\mathbf{3 2 , 1}$ & $\mathbf{2 3 , 1}$ & $\mathbf{1 6 , 9}$ & $\mathbf{2 5 , 3}$ \\
\hline Privada & 13,5 & 11,4 & 2,3 & 1,8 & 9,9 \\
\hline Pública & 9,8 & 20,7 & 20,8 & 15,1 & 15,4 \\
\hline Educação presencial & $\mathbf{7 6 , 7}$ & $\mathbf{6 7 , 9}$ & $\mathbf{7 6 , 9}$ & $\mathbf{8 3 , 1}$ & $\mathbf{7 4 , 7}$ \\
\hline Privada & 43,0 & 25,3 & 9,1 & 28,6 & 31,3 \\
\hline Pública & 33,7 & 42,5 & 67,8 & 54,5 & 43,4 \\
\hline Total de ingressos em 2009 & 34.329 & 27.946 & 8.917 & 12.235 & 83.427 \\
\hline
\end{tabular}

Fonte: Inep, Microdados do Censo da Educação Superior 2009 
